\title{
The Results of the Single Center Pilot Randomized Russian Clinical Trial of Mesenchymal Stromal Cells in Severe Neutropenic Patients with Septic Shock (RUMCESS)
}

\author{
Gennadiy Galstyan*, Polina Makarova, Elena Parovichnikova, Larisa Kuzmina, Vera \\ Troitskaya, Eduard Gemdzhian and Valeriy Savchenko
}

National Research Center for Hematology, Moscow, Russia

*Corresponding author: Gennadiy Galstyan, National Research Center for Hematology, Moscow, Russia

\begin{abstract}
Purpose: To investigate the safety of the of bone marrow-derived human multipotent mesenchymal stromal cells (MMSCs) administration in neutropenic patients with septic shock.

Methods: A single center prospective randomized Russian clinical trial of MMSCs in neutropenic patients with septic shock was registered (RUMCESS) (NCT 01849237). The patients were randomly assigned to receive conventional therapy $(C T)(n=15)$ or intravenous MMSCs $+C T(n=15)$ at the dose of $1 \times 10^{6} \mathrm{MMSCs} / \mathrm{kg}$.
\end{abstract}

Results: Initial SOFA scores were 15.9 (95\% Cl 13.9-20.2) in MMSCs + CT and 16.1 (95\% Cl 12.1-19.0) in CT group. For second day cardiovascular component of SOFA and $\mathrm{PaO}_{2} / \mathrm{FiO}_{2}$ improved in MMSC + CT group. 28-days survival rates were $20 \%(3 / 15$ patients) in CT group and $60 \%(9 / 15$ patients) in the MMSC + CT group $(P<0.05)$. In MMSC + CT group only 4 patients remained alive in 3 months, 5 patients died due to the infection related organ dysfunctions, in CT group 3 patients remained alive in 3 months.

Conclusions: Administration of MMSCs in neutropenic patients with septic shock was well tolerated and attributed to the faster hemodynamic stabilization, vasopressor withdrawal, attenuation of respiratory failure and shortening of the neutropenia duration period.

\section{Keywords}

Septic shock neutropenia, Multipotent mesenchymal stromal cells, Neutropenia

\section{Abbreviations}

ANC: Absolute neutrophil count, CLP: Cecal ligation and puncture, CT: Conventional therapy, $\mathrm{Cl}$ : Confidence Interval,
DMSO: Dimethyl Sulphoxide, HSCT: Hematopoietic Stem Cell Transplantation, ICU: Intensive Care Unit, IQR: Interquartile Range, MMSCs: Multipotent Mesenchymal Stromal Cells, PBS: Phosphate Buffered Saline, RUMCESS: Russian Clinical Trial of Mesenchymal Cells in patients with Septic Shock and Severe Neutropenia, SOFA: Sequential Organ Failure Assessment, Th: T-helper, WBC: White Blood Cell

\section{Introduction}

Mesenchymal stromal cells (MMSCs) may represent a promising cell-based therapy of sepsis. MMSCs, activated by lipopolysaccharide or tumor necrosis factor- $\alpha$, reprogram macrophages by releasing prostaglandin E2. Prostaglandin E2 acts on the macrophages through the EP2 and EP4 receptors and stimulates the production and release of an anti-inflammatory cytokine interleukin-10 (IL-10) [1]. The protective effects of MMSCs in sepsis may also include a direct antimicrobial activity against pathogens. MMSCs secrete the anti-microbial peptide LL-37 in response to stimulation by Escherichia coli [2]. The MMSC administration prevented endotoxin-induced lung inflammation, injury and edema in mice. Administration of MMSCs into the airspaces of the lung decreased in lung water and bronchoalveolar lavage protein and increased the survival after the intrapulmonary administration of endotoxin compared with PBS-treated control mice [3]. Animal trials have provided evidence that an intravenous injection of MMSCs can improve survival in septic animals. In study

Citation: Galstyan G, Makarova P, Parovichnikova E, Kuzmina L, Troitskaya V, et al. (2018) The Results of the Single Center Pilot Randomized Russian Clinical Trial of Mesenchymal Stromal Cells in Severe Neutropenic Patients with Septic Shock (RUMCESS). Int J Blood Res Disord 5:033. doi. org/10.23937/2469-5696/1410033

Accepted: October 10, 2018: Published: October 12, 2018

Copyright: (c) 2018 Galstyan G, et al. This is an open-access article distributed under the terms of the Creative Commons Attribution License, which permits unrestricted use, distribution, and reproduction in any medium, provided the original author and source are credited. 
of Krasnodembskaya, et al. [4] peritoneal gram-negative sepsis in mice was induced by injection into the peritoneum Pseudomonas aeruginosa. After $1 \mathrm{~h}$, the MMSCs in phosphate buffered saline (PBS), or fibroblast cells in PBS, or PBS were injected intravenously. Survival rate within $48 \mathrm{~h}$ was significantly higher in the mice treated with MMSCs compared to the mice treated with fibroblasts or PBS only. Nemeth, et al. [1] looked at survival rates after sepsis induced by cecal ligation and puncture (CLP) in untreated and MMSC-treated mice. There was an improvement in the survival rate of mice given $1 \times$ $10^{6}$ MMSCs intravenously at the time of surgery. The beneficial effect on survival was also seen when the cells were injected $24 \mathrm{~h}$ before or $1 \mathrm{~h}$ after CLP. In contrast, intravenous injection of isolated skin fibroblasts, whole bone marrow or heat-killed MMSCs did not alter the survival [1]. In the sepsis induced by CLP in the ab- sence of antibiotic therapy, the treatment with MMSCs significantly improved the survival rate compared to the septic mice that received normal saline (58\% vs. 30\%) [5].

No study has investigated the effects of the MMSC therapy on the survival of the patients with septic shock. We hypothesized that MMSC therapy is safe in neutropenic patients with septic shock. The objective of this study was to assess the safety of bone marrow-derived human MMSCs for the treatment of septic shock in neutropenic patients.

\section{Materials and Methods}

\section{Study design}

The Russian clinical trial of Mesenchymal Cells in patients with Septic Shock and Severe Neutropenia

Table 1: Baseline characteristics of MMSC plus conventional therapy treated patients and conventional therapy treated patients (at onset of septic shock prior to randomization).

\begin{tabular}{|c|c|c|}
\hline Parameter & $\begin{array}{l}\text { MMSCs + Conventional therapy } \\
(n=15)\end{array}$ & Conventional therapy $(n=15)$ \\
\hline $\begin{array}{l}\text { Time interval from the onset of septic shock to } \\
\text { randomization (hours), Me (IQR) }\end{array}$ & $5(4-7)$ & $5.5(3-8)$ \\
\hline Age (years) Me (ranges) & $40(30-75)$ & $47(33-81)$ \\
\hline Male/Female (n) & $6 / 9$ & $7 / 8$ \\
\hline \multicolumn{3}{|l|}{ Underlying diseases } \\
\hline Acute myeloid leukemia & 5 & 4 \\
\hline Myelodysplastic syndrome & 1 & 1 \\
\hline Non-Hodgkin's lymphoma & 6 & 5 \\
\hline Multiple myeloma & 1 & 3 \\
\hline Renal transplantation & 1 & 1 \\
\hline Hodgkin's lymphoma & 0 & 1 \\
\hline Acute lymphoblastic leukemia & 1 & 0 \\
\hline \multicolumn{3}{|l|}{ Number of the patients received } \\
\hline Chemotherapy & 11 & 12 \\
\hline Immunosuppressive therapy & 1 & 2 \\
\hline HSCT & 3 & 1 \\
\hline $\begin{array}{l}\text { Time from the end of the chemotherapy to } \\
\text { randomization (days), Me (ranges) }\end{array}$ & $7(1-64)$ & $8(0-21)$ \\
\hline APACHE II score, Me (IQR) & $33.5(26.3-36.0)$ & $34.0(27-36)$ \\
\hline SOFA score, Me (IQR) & $16.0(15.0-17.0)$ & $16.5(15.0-17.8)$ \\
\hline Noradrenaline doses, Me (IQR) & 1.0 (IQR 0.5-1.75) & 1.4 (IQR 0.6-1.9) \\
\hline Serum lactate concentrations, $\mathrm{mmol} / \mathrm{l}, \mathrm{Me}(\mathrm{IQR}), \mathrm{mmol} / \mathrm{l}$ & $3.5(2.9-4.5)$ & $3.5(2.5-4.2)$ \\
\hline Mechanically ventilated patients & 8 & 4 \\
\hline Patients required renal replacement therapy & 5 & 4 \\
\hline Positive blood cultures & $\begin{array}{l}\text { - } \text { Pseudomonas aeruginosa + } \\
\text { Staphylococcus haemolyticus [1], } \\
\text { - Pseudomonas aeruginosa + } \\
\text { Enterococcus faecium [1], } \\
\text { - Escherichia coli [2], } \\
\text { - Klebsiella pneumoniae [3], } \\
\text { - Klebsiella oxytoca [1], } \\
\text { - Pseudomonas aeruginosa + } \\
\text { Escherichia coli [1] } \\
\text { - Escherichia coli [1], } \\
\text { - Sphingobacterium multivorum [1] } \\
\text { - Stenotrophomonas maltophilia + } \\
\text { Klebsiella pneumoniae [1], } \\
\text { - Candida albicans [1] }\end{array}$ & $\begin{array}{ll}\text { - } & \text { Acinetobacter baumannii + } \\
& \text { Klebsiella pneumoniae [2] } \\
\text { - } & \text { Klebsiella pneumoniae + } \\
& \text { Enterococcus faecium [1] } \\
\text { - } & \text { Pseudomonas aeruginosa } \\
& {[1]} \\
\text { - Klebsiella pneumoniae [1] } \\
\text { - Enterococcus faecium [2], } \\
\text { - Candida krusei [1] } \\
\text { - Candida tropicalis [1] } \\
\text { - Acromonium [1] }\end{array}$ \\
\hline
\end{tabular}


(RUMCESS) (ClinicalTrials.gov NCT 01849237) is a single centre, open-label, randomized, controlled trial comparing conventional therapy (CT) of septic shock with combined MMSCs and CT in neutropenic patients. The study protocol was conducted according to the Declaration of Helsinki and approved by the institutional ethics committee (DHHS IRB Registration \# 00003348, Board meeting record No 89-2012. The trial was regulated and conformed to the Russian Federal health legislation. Written informed consent was obtained from all the patients or their next of kin (in mechanically ventilated or sedated patents) before inclusion in the study by intensive care unit (ICU) researchers (G.G or P.M.).

\section{Patients}

Patients 18 years of age or older with severe neutropenia (White blood cell count (WBC) or absolute neutrophil count $\left.(\mathrm{ANC})<0.5 \times 10^{9} / \mathrm{l}\right)$ with nonterminal hematological disorders with life expectancy of 6 months and admitted to the ICU due to septic shock were included in this study (Table 1). We included in the study neutropenic patients with de novo malignancies, after induction remission chemotherapy and after hematopoietic stem cell transplantation (HSCT) or renal transplantation. In these patients a life expectancy was more than 6 months. Exclusion criteria were the following: Age less than 18 years, another form of shock, pregnancy, WBC or ANC $>0.5 \times 10^{9} / l,>10$ hours from shock onset. The chemotherapy resistant patients and the patients with relapses of malignancies were not included in the study.

The patients were randomly assigned $(1: 1)$ to receive CT of septic shock $(n=15)$ either MMSCs + CT ( $n$ $=15$ ). The computer-generated and blind assignment sequence was used for randomization by the study coordinator (L.K.). Investigators were not informed about the allocation sequence before the patient was enrolled into the clinical trial. Block randomization was used; The blocks consisted of two elements and were distributed in a random sequence.

\section{Treatment}

The knowledge of the treatment assignment did not influence the treatment. The ICU doctors who did not know about application of MMSCs accepted all decisions on prescription of antibiotics, application of life support techniques, etc. The CT of septic shock consisted of antibiotic treatment, fluid resuscitation and vasopressors according to the institutional protocol and Surviving Sepsis Campaign guidelines [6]. Because there is no current evidence supporting the routine use of Granulocyte-colony stimulating factor (G-CSF) in patients with sepsis [7] none of our patients received G-CSF. All patients received intravenous antibiotic therapy, which was prescribed by ICU doctors within the first hour of recognition of septic shock. Initial empiric anti-infective therapy included the drugs that have an activity against the likely pathogens. The antimicrobial regimens were reassessed on the basis of microbiological data. Appropriateness of the antibiotic therapy was based on the identification of the pathogens isolated in either the site or in the blood cultures. All septic shock patients received hydrocortisone $200 \mathrm{~m} /$ day for 7 days as continuous infusion. Mechanical ventilation in the patients with respiratory failure and hemofiltration in the patients with renal failure were performed. The intravenous infusion of MMSCs at the dose $1 \times 10^{6} / \mathrm{kg}$ was performed within the first 10 hours of septic shock. The rationale for the dose of MMSCs were the same doses in Canadian trial Cellular Immunotherapy for Septic Shock (CISS) (ClinicalTrials.gov Identifier: NCT02421484) (3 dose cohorts will receive doses of 0.3 million cells/ $\mathrm{kg}, 1.0$ million cells $/ \mathrm{kg}$, and 3.0 million cells $/ \mathrm{kg}$ ), as well the efficacy and safety of MMSC administration at the doses of $0.9-1.3 \times 10^{6} / \mathrm{kg}$ for acute graft-versus-host disease prophylaxis in hematological patients those were shown in our previous study [8].

\section{Definitions}

Sepsis was defined according to the criteria of Surviving sepsis campaign [6]. Septic shock was defined as development in septic patient's systolic blood pressure less than $90 \mathrm{mmHg}$, not responding to the appropriate fluid resuscitation, and requiring vasopressors to maintain mean arterial pressure greater than or equal to 65 $\mathrm{mmHg}$ and serum lactate level $>2 \mathrm{mmol} / \mathrm{I}$ [6]. Only patients who needed norepinephrine were included in the study. Acute respiratory failure was defined as $\mathrm{PaO}_{2} /$ $\mathrm{FiO}_{2}<300$. Acute renal failure was defined as the urine output $<0.5 \mathrm{ml} / \mathrm{kg} / \mathrm{h}$ for $1 \mathrm{~h}$ or serum creatinine $\geq 2 \mathrm{mg} /$ dl. Liver dysfunction was defined as total bilirubin level of greater than $2 \mathrm{mg} / \mathrm{dL}$ (> $34 \mu \mathrm{mol} / \mathrm{L}$ ) and either serum aminotransferase level of greater than twice the normal value. All patients were thrombocytopenic $(<50 \times$ $\left.10^{9} / \mathrm{l}\right)$. Acute Physiology and Chronic Health Evaluation (APACHE) II scores [9] and sequential organ failure assessment (SOFA) scores [10] were calculated.

\section{Outcomes}

The primary outcome was the safety of MMSC therapy. Any adverse effects after MMSCs administration, the death from any cause within 28 days after randomization, organ dysfunctions, duration of neutropenia period and death from any cause at 90 days after randomization were also analysed.

\section{Statistical analysis}

Data were analysed with Statistical Analysis Software (SAS, version 9.3, SAS Institute Inc., Cary, NC). The variables were expressed as mean and $95 \%$ confidence intervals (Cl), Standard Deviation (SD) or median (Me) and interquartile range (IQR), categorical variables were expressed as frequency and percentage. The compliance of continuous data with the normal distribution was investigated using the Shapiro-Wilk test. The groups 
conforming to the normal distribution were compared using independent samples two-tailed t-test (paired or unpaired). When the distribution was not normal Mann-Whitney or Wilcoxon signed-rank test was used. The relationship between categorical variables was analysed using Fisher's exact test. For statistical analysis of indicator dynamics repeated measures analysis was used. The Kaplan-Meier method (with the log-rank test) and the Cox proportional hazard regression model were used to evaluate the difference between the overall survival rate in patients treated with the CT or with the MMSCs + CT. The sample size in this trial was determined by the difficulties in recruiting of patients. A $p$-value of $<0.05$ was considered significant in the results of analysis.

$$
<10 \mathrm{~h}
$$
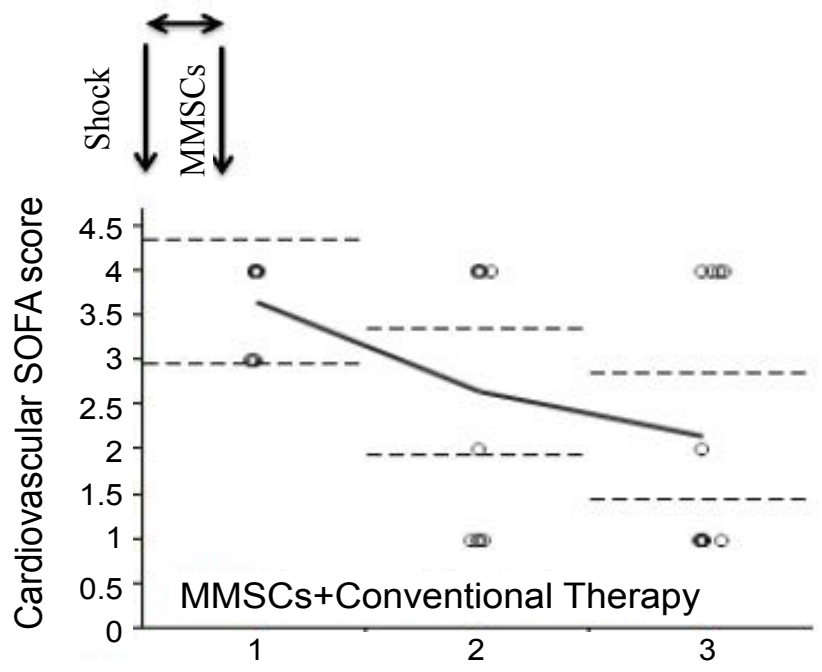

Time from onset of septic shock (days)

\section{Results}

From June 2013 through December 2015, a total of 68 patients with septic shock were admitted in the ICU. Though 20 patients with septic shock had the WBC count more than $0.5 \times 10^{9} / \mathrm{I}$ and 18 patients with septic shock had a poor prognosis of hematological malignancies, they were not enrolled in the study. Thus, 30 neutropenic patients with septic shock were included in this study. The patients were distributed into two groups: $\mathrm{CT}$ group and MMSC + CT group. There were no significant differences between the groups in demographic parameters, in the time interval from the onset of septic shock to randomization and in the hematological disorders. In all patients the neutropenia has developed
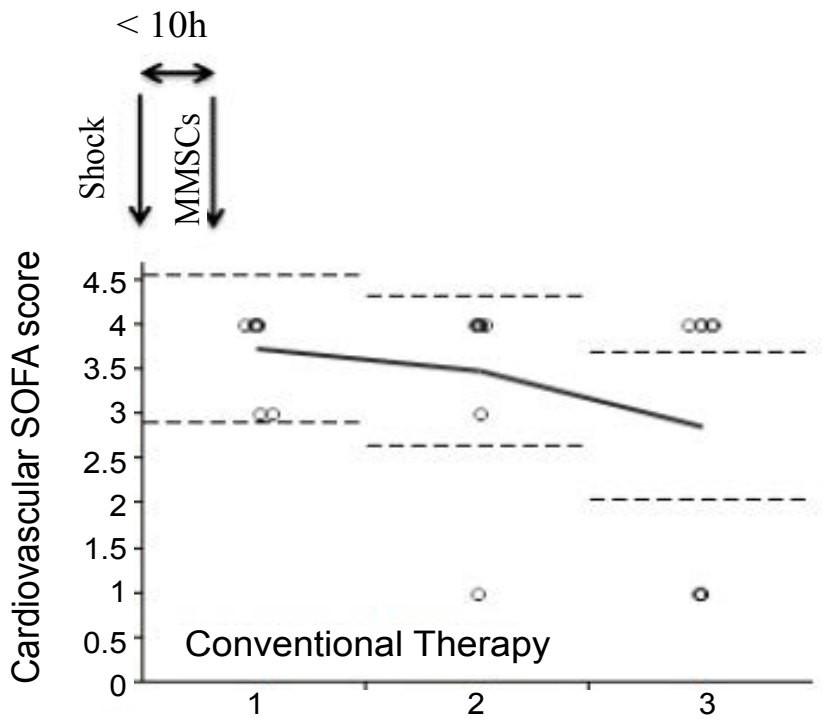

Time from onset of septic shock (days)

$<10 \mathrm{~h}$
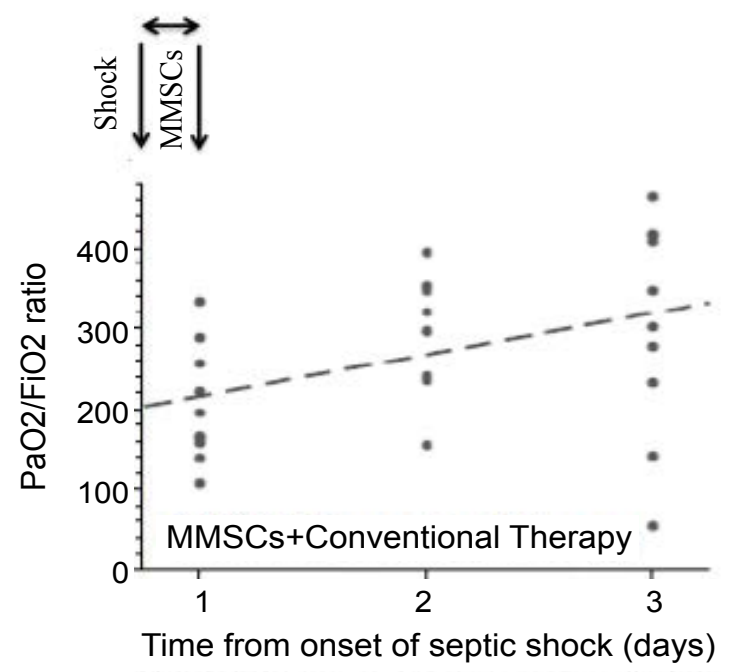

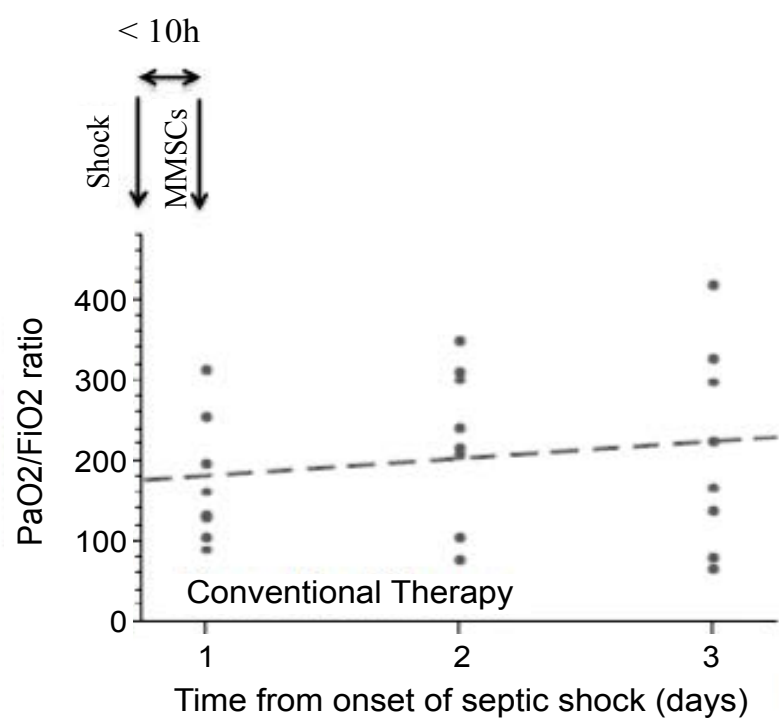

Figure 1: Cardiovascular SOFA scores and $\mathrm{PaO}_{2} / \mathrm{FiO}_{2}$ ratio changes in patients during the first three days of septic shock. The open circles represent values of the cardiovascular SOFA, the solid lines connect means and the dashed lines represent $95 \% \mathrm{Cl}$. The circles represent values. Dashed lines represent linear regression lines of $\mathrm{PaO}_{2} / \mathrm{FiO}_{2}$. 
after chemotherapy or immunosuppressive therapy. In 3 patients from the MMSC + CT group the neutropenia has developed after allogeneic HSCT (Table 1). Prior to randomization there were no significant differences between two groups in serum lactate levels, in the requirement of renal replacement therapy, in APACHE II and SOFA scores, in the mean arterial pressure and in the need of vasopressors (Table 1). Prior to randomization patients from the MMSC + CT group were a bit more often mechanically ventilated $(8 / 15$ patients vs. $4 / 15$ patients, Fisher's exact test, $p=0.14$ ).

Positive blood cultures were documented in 13 of 15 patients in the MMSC + CT group and in 10 of 15 patients in the CT group. The gram-negative bacteremia dominated, the gram-positive bacteria were isolated from the blood less often (Table 1). Fungal pathogens were isolated from the blood in 4 patients.

MMSCs at the dose of $1 \times 10^{6} / \mathrm{kg}$ were injected intravenously into 15 patients from the MMSC-CT group. All patients tolerated the MMSC infusion well and no infusion-related reactions (fever, rigors, chills, myalgias, arthralgias, nausea, vomiting, headaches, bronchospasm) were observed. No patient suffered any immediate complication or respiratory or cardiovascular compromise.

During the study the total SOFA score was not significantly different between the groups. However, during the first three days the means of cardiovascular SOFA scores decreased in MMSC + CT group from $3.73(95 \% \mathrm{Cl}$ 3.48-3.99) to 2.17 ( $95 \% \mathrm{Cl} 1.28-3.06$ ), t-test, $p=0.01$, regression coefficient -0.75 . In the CT group the decrease of the means of cardiovascular SOFA scores was not significant from $3.75(95 \% \mathrm{Cl} 3.36-4.14)$ to $2.82(95 \% \mathrm{Cl}$ 1.58-4.17), t-test, $p=0.13$ regression coefficient -0.44 (Figure 1). Since the fourth day there were no differences in the cardiovascular SOFA scores in survived patients from both groups. In the MMSC-CT group the median of noradrenaline doses was 1.0 (IQR $0.5-1.75) \mathrm{mcg} / \mathrm{kg} /$ $\mathrm{min}$, in CT group the median of noradrenaline doses was 1.4 (IQR 0.6-1.9) $\mathrm{mcg} / \mathrm{kg} / \mathrm{min}$.

At the onset of septic shock there were no differences in $\mathrm{PaO}_{2} / \mathrm{FiO}_{2}$ ratio between $\mathrm{MMSC}+\mathrm{CT}$ and $\mathrm{CT}$ groups. In three days, the means of $\mathrm{PaO}_{2} / \mathrm{FiO}_{2}$ ratio increased in the MMSC + CT group from $205.0(95 \% \mathrm{Cl}$ 154.1-256.0) to 308.3 (95\% Cl 213.1-403.5), t-test, $\mathrm{p}=$ 0.05 , regression coefficient 51.6 . In the $\mathrm{CT}$ group the changes of the means of $\mathrm{PaO}_{2} / \mathrm{FiO}_{2}$ ratio were not significant: From 174.0 (95\% Cl 109.1-238.9) to 215.3 (95\% $\mathrm{Cl}$ 110.6-321.1), $p=0.27$, regression coefficient 20.7 and increase of $\mathrm{PaO}_{2} / \mathrm{FiO}_{2}$ was observed only a week later (Figure 1).

In the MMSC + CT group the acute respiratory failure was observed in $13 / 15$ patients. In this group $11 / 15$ patient needed mechanical ventilation: 8 patients were intubated prior to randomization and 3 patients were in- tubated after randomization. In the CT group the acute respiratory failure was observed in $13 / 15$ patients. Four of them needed mechanical ventilation prior to randomization and 6 patients were intubated after randomization. Thus, in CT group 10/15 patients were mechanically ventilated. On the second day of septic shock $\mathrm{PaO}_{2} / \mathrm{FiO}_{2}$ significantly elevated in the $\mathrm{MMSC}+\mathrm{CT}$ group $(p<0.05)$ and became higher $(p=0.019)$ than in the CT group (Me 248, IQR 216-354 and Me 178, IQR 110-257, respectively).

The acute renal failure was revealed in $9 / 15$ patents in the MMSC + CT group, 7 of them required renal replacement therapy. In the CT group the acute renal failure was observed in $9 / 15$ patients, all of them required renal replacement therapy. Liver dysfunction was revealed in 7 of 15 patients in the MMSC + CT group and in 6 of 15 patients in the CT group.

On the first day of septic shock the patients from the $\mathrm{MMSC}+\mathrm{CT}$ and the $\mathrm{CT}$ groups had severe neutropenia and low WBC (Me $0.2 \times 10^{9} / \mathrm{l}$, IQR 0.1-0.35 $\times 10^{9} / \mathrm{I}$ and Me $0.3 \times 10^{9} /$ I, IQR $0.1-0.4 \times 10^{9} /$ l, respectively). In the MMSC + CT group the increase of WBC comparing to the first day of shock was registered on the $7^{\text {th }}$ day (Me $3.8 \times 10^{9} / \mathrm{I}$, IQR $\left.1.0-8.2 \times 10^{9} / \mathrm{I}\right)$. To the end of the 28-day follow up period $4 / 9$ of the patients from the MMSC + CT group had $\mathrm{WBC}<1 \times 10^{9} / \mathrm{I}$. In the CT group a significant increase of WBC was registered only on the 14th day, but on the $28^{\text {th }}$ day all 3 survived patients had WBC $>1 \times 10^{9} /$ l.

The MMSC + CT was associated with a significant increase of the 28-day overall survival rate in comparison with the CT (respectively, survived 9 of 15 patients vs. 3 of $15 ; p=0.05$ ) and a decrease of the risk of death (HR 0.40; 95\% $\mathrm{Cl} 0.10-0.80 ; \mathrm{p}=0.04$ ). During this period in the CT group the causes of the death were refractory shock [6], multiple organ failure [5], cardioembolic stroke [1]. In the MMSC + CT group the causes of the death were refractory shock [2], multiple organ failure [2] and respiratory failure [1]. The CT treated patients died earlier than MMSC + CT treated patients. The median time between the randomization and the death was 6.5 (IQR 2.0-10.0) hours for 12 CT-treated patients and 12.0 (IQR 11.1-14.2) hours for $6 \mathrm{MMSC}+\mathrm{CT}$-treated patients (Mann-Whitney test, $\mathrm{p}=0.048$ ).

Although the 28-days survival rate in MMSC + CT group was higher, this effect of MMSCs was only temporary and there was no difference in overall survival between the groups after 3 months. In the CT group all patients were alive after 3 months. In the MMSC + CT one patient died on the $72^{\text {nd }}$ day due to the pulmonary embolism, three patients remained neutropenic and died on the 29,30 and 33 days after the randomization due to the repeated septic shock. One patient with multiple myeloma died on the 89th day due to infectious complications and multiple organ failure. 


\section{Discussion}

This is the first randomized clinical trial that studied the MMSC infusion in neutropenic patients with septic shock. The study demonstrated the safety of the MMSC therapy for patients with septic shock. Our data are agreed with the results of CISS study [11]. In CISS phase I trial freshly cultured allogeneic bone-marrow-derived MMSCs in doses up to 250 million cells were safe to administer to patients with septic shock [11]. We also observed no adverse effects after MMSC administration and noted the amelioration of organ dysfunction in patients with septic shock.

The MMSCs were cryopreserved in DMSO. Cryopreservatives are necessary additives to stem cell concentrates, since they inhibit the formation of intra and extracellular crystals and hence cell death. The standard cryoprotectant is DMSO, which prevents freezing damage to living cells [12]. No guidelines exist for DMSO usage [13]. The use of $10 \%$ DMSO for bone marrow transplantation was associated with an overall incidence of toxicity of $1.5 \%$, while the use of DMSO reduction strategies was associated with an overall toxicity incidence of $0.3 \%$ [12]. DMSO reduction strategies include using concentration of DMSO $<10 \%$ or washing of cells before return. Only 5 bone marrow transplant centres exclusively washed cells before return while 12 did so sometimes [13]. We did not wash MMSCs before infusion. In our study initial solution of cryopreserved MMSCs in 10\% DMSO has been diluted 2-4 times with Dextran before infusion. The upper limit in the amount of DMSO given per day in European transplant centres was $80 \mathrm{~g}$ [13]. We administrated only 0.5-1 g of DMSO and did not observe any adverse effects.

We found that mortality rate on the 28th day was lower in the MMSC + CT group than in the CT group. However, this effect was temporary and on the $90^{\text {th }}$ day the mortality rate was the same. This phenomenon may reflect the safety of MMSC therapy and may be explained by attenuation of organ failure. Infusion of MMSCs allowed the reduction of the doses and withdrawal of vasopressors faster than in patients treated only with $\mathrm{CT}$.

The other beneficial effect of MMSC treatment was the attenuation of respiratory failure. Prior to randomization more patients from the MMSC $+\mathrm{CT}$ group were ventilated, but this difference was statistically non-significant. There were no statistically significant differences also in $\mathrm{PaO}_{2} / \mathrm{FiO}_{2}$ ratios between the groups. This phenomenon can be explained by beneficial effect of positive end-expiratory pressure in mechanically ventilated patients. $\mathrm{PaO}_{2} / \mathrm{FiO}_{2}$ elevated significantly after MMSC administration. We are not the first ones who describe this effect of MMSCs: In the experimental study [3]. These effects of MMSCs were explained by down-regulation of pro-inflammatory responses to en- dotoxin and increasing the anti-inflammatory cytokine IL-10 [14]. Chang, et al. [15]. reported a case history of a 59-yr-old patient who was treated with MMSCs in the course of ARDS and subsequent pulmonary fibrosis. During next three days after the intratracheal administration of MMSCs at a dose of $1 \times 10^{6} / \mathrm{kg}$, the authors observed an improvement in patient's mental status, lung compliance, $\mathrm{PaO}_{2} / \mathrm{FiO}_{2}$ ratio and chest radiography.

The feature of our study was the fact that it was carried out in neutropenic patients. Neutropenia is associated with an increased risk of death in septic shock patients [16]. As long as patients are neutropenic it is likely that some of them will develop infectious complications [17]. Septic shock in neutropenic patients is an illness associated with high morbidity and mortality and independent prognostic factor of death. Mortality from septic shock in neutropenic patients rated 55.5\% [18]. In the septic shock patients with hematological malignancies requiring a combination of life support techniques such as mechanical ventilation, hemodialysis, vasopressors and hematologic support, the mortality rose to 69$83 \%$ [19]. The administration of MMSCs in neutropenic patients with septic shock shortened the neutropenia period. Our data doesn't match with the results of Hall, et al. [20]. They have shown that in mice model of polymicrobial sepsis beneficial effects of MMSCs were lost after depleting neutrophils in recipient mice. Our data suggest that MMSCs are safe in neutropenic patients with septic shock and can attenuate the course of septic shock. Immediately after the MMSC administration we did not observe any adverse effects and changes of heart rate, mean arterial pressure, of vasopressors and $\mathrm{PaO}_{2} / \mathrm{FiO}_{2}$. However, in three days cardiovascular SOFA scores and $\mathrm{PaO}_{2} / \mathrm{FiO}_{2}$ have been improved in $\mathrm{MMSC}+$ $\mathrm{CT}$ group. The lethal outcomes in the CT group occurred earlier than in the MMSC + CT group (median time 6 hours vs. 12 hours, $p=0.048$ ). The lethal outcomes in the $\mathrm{CT}$ group occurred earlier than in the MMSC + CT group (median time 6 hours vs. 12 hours, $\mathrm{p}=0.048$ ). However, despite higher 28-day survival in MMSC treated group nearly a half of MMSC treated patients had died later of sepsis related complications. Thus, MMSCs had transient survival impact. This phenomenon can be explained with the brief and temporary period of the biological activity of infused MMSCs that does not persist beyond $24 \mathrm{~h}$ [21]. One hour after intravenous administration $83 \%$ of MMSCs were distributed in the lungs, in $24 \mathrm{~h}$ only $42 \%$ of MMSCs were found in the lungs and after one week - less than $0.001 \%$ [22]. Several authors suggested sustaining a long-term biological response by greater frequency of MMSC administration [21]. In our study single administration of MMSCs allows getting over for short time septic shock, but not sepsis related complications and organ failure and doesn't prevent death from sepsis related organ dysfunctions for a long period. Perhaps, the repeated administration of MMSCs is required. 
In conclusion, this study demonstrates that intravenous administration of MMSCs at a dose of $1 \times 10^{6}$ MMSCs/kg during the first 10 hours was well tolerated and provided an advantage in neutropenic patients with septic shock that could be attributed to the faster hemodynamic stabilization, vasopressor withdrawal, attenuation of respiratory failure and shortening of the neutropenia period. These findings are the first evidence that intravenous administration of MMSCs is safe and has beneficial effects in the patients with septic shock. However, single MMSC administration doesn't prevent death from the sepsis related organ dysfunctions. Despite the fact that the MMSC-treatment has improved a course of septic shock within 28 days, most of the survived patients remained immunocompromised, neutropenic and infected. In the most cases the infection was a cause of death of the patients after 28 days. MMSC-treatment can attenuate the shock related organ dysfunction but does not lead to the infection eradication in immunocompromised patients.

\section{Limitations}

The limitations of this study were single centre, open-label design and small sample size. The findings require validation in larger studies. Only in an o pen label trial, it is impossible to say that knowledge of the treatment assignment did not influence care or decisions about treatment. The knowledge of the treatment assignment could influence a physician's decision to initiate new treatment, continue treatment or change direction of care to comfort and allow a patient to pass away. Future randomized controlled double-blind trial is essential to prevent the possibility of treatment biases. This study demonstrated safety of MMSC treatment in neutropenic patients with septic shock. However randomized placebo-controlled trials are required to prove MMSC efficiency in patients with septic shock.

This research did not receive any specific grant from funding agencies in the public, commercial, or not-forprofit sectors.

\section{Competing Interests}

The authors declare they have no competing interests.

\section{Acknowledgments}

The authors thank Nina Drize and Nataliya Petinati for the extension and testing MMSCs used in this trail.

Trial protocol can be accessed on https://clinicaltrials.gov/ ct2/show/NCT01849237?term=NCT01849237\&rank=1

\section{References}

1. Németh $K$, Leelahavanichkul A, Yuen PST, Mayer B, Parmelee A, et al. (2009) Bone marrow stromal cells attenuate sepsis via prostaglandin $\mathrm{E}(2)$-dependent reprogramming of host macrophages to increase their interleukin-10 production. Nat Med 15: 42-49.
2. Krasnodembskaya A, Song $Y$, Fang X, Gupta N, Serikov $V$, et al. (2010) Antibacterial effect of human mesenchymal stem cells is mediated in part from secretion of the antimicrobial peptide LL-37. Stem Cells 28: 2229-2238.

3. Xu J, Woods CR, Mora AL, Joodi R, Brigham $\mathrm{KL}$, et al. (2007) Prevention of endotoxin-induced systemic response by bone marrow-derived mesenchymal stem cells in mice. Am J Physiol Lung Cell Mol Physiol 293: 131-141.

4. Krasnodembskaya A, Samarani G, Song Y, Zhuo H, Su $X$, et al. (2012) Human mesenchymal stem cells reduce mortality and bacteremia in gram-negative sepsis in mice in part by enhancing the phagocytic activity of blood monocytes. Am J Physiol Lung Cell Mol Physiol 302: 1003-1013.

5. Luo C, Zhang F, Zhang L, Geng Y, Li Q, et al. (2014) Mesenchymal stem cells ameliorate sepsis-associated acute kidney injury in mice. Shock 41: 123-129.

6. Dellinger R, Levy M, Rhodes A, Annane D, Gerlach H, et al. (2013) Surviving sepsis campaign: International guidelines for management of severe sepsis and septic shock: 2012. Crit Care Med 41: 580-637.

7. Bo L, Wang F, Zhu J, Li J, Deng X (2011) Granulocyte-colony stimulating factor (G-CSF) and granulocyte-macrophage colony stimulating factor (GM-CSF) for sepsis: A meta-analysis. Crit Care 15: 58.

8. Kuzmina LA, Petinati NA, Parovichnikova EN, Lubimova LS, Gribanova EO, et al. (2012) Multipotent Mesenchymal Stromal Cells for the Prophylaxis of Acute Graft-versus-Host Disease - A Phase II Study. Stem Cells Int 2012: 968213.

9. Knaus WA, Draper EA, Wagner DP, Zimmerman JE (1985) APACHE II: A severity of disease classification system. Crit Care Med 13: 818-829.

10. Vincent JL, Moreno R, Takala J, Willatts S, De Mendonça A, et al. (1996) The SOFA (Sepsis-related Organ Failure Assessment) score to describe organ dysfunction/failure. On behalf of the Working Group on Sepsis-Related Problems of the European Society of Intensive Care Medicine. Intensive Care Med 22: 707-710.

11. Mcintyre LA, Stewart DJ, Mei SHJ, Courtman D, Watpool I, et al. (2018) Cellular immunotherapy for septic shock (CISS): A Phase I clinical trial. Am J Respir Crit Care Med 197: 337-347.

12. David Berz, Elise M McCormack, Eric S Winer, Gerald A Colvin, Peter J Quesenberry (2007) Cryopreservation of hematopoietic stem cells. Am J Hematol 82: 463-472.

13. Windrum $P$, Morris TCM, Drake MB, Niederwieser D, Ruutu $\mathrm{T}$, et al. (2005) Variation in dimethyl sulfoxide use in stem cell transplantation: A survey of EBMT centres. Bone Marrow Transplant 36: 601-603.

14. Gupta N, Su X, Popov B, Lee JW, Serikov V, et al. (2007) Intrapulmonary delivery of bone marrow-derived mesenchymal stem cells improves survival and attenuates endotoxin-induced acute lung injury in mice. J Immunol 179: 1855-1863.

15. Chang Y, Park SH, Huh J-W, Lim C-M, Koh Y, et al. (2014) Intratracheal administration of umbilical cord blood-derived mesenchymal stem cells in a patient with acute respiratory distress syndrome. J Korean Med Sci 29: 438-440.

16. Tolsma V, Schwebel C, Azoulay E, Darmon M, Souweine B, et al. (2014) Sepsis severe or septic shock. Outcome according to immune status and immunodeficiency profile. Chest 146: 1205-1213. 
17. Bodey GP, Buckley M, Sathe Y, Freireich E (1966) Quantitative relationships between circulating leukocytes and infection in patients with acute leukemia. Ann Intern Med 64: 328-340.

18. Larché J, Azoulay E, Fieux F, Mesnard L, Moreau D, et al. (2003) Improved survival of critically ill cancer patients with septic shock. Intensive Care Med 29: 1688-1695.

19. Massion PB, Dive AM, Doyen C, Bulpa P, Jamart J, et al. (2002) Prognosis of hematologic malignancies does not predict intensive care unit mortality. Crit Care Med 30: 2260-2270.
20. Hall SRR, Tsoyi K, Ith B, Padera RF, Lederer JA, et al. (2013) Mesenchymal stromal cells improve survival during sepsis in the absence of heme oxygenase-1: The importance of neutrophils. Stem Cells 31: 397-407.

21. Parekkadan B, Milwid JJ (2010) Mesenchymal stem cells as therapeutics. Annu Rev Biomed Eng 12: 87-117.

22. Lee RH, Pulin AA, Seo MJ, Kota DJ, Ylostalo J, et al. (2009) Intravenous hMSCs improve myocardial infarction in mice because cells embolized in lung are activated to secrete the anti-inflammatory protein TSG-6. Cell Stem Cell 5: 54-63. 